\title{
Brunner Gland Adenoma of Duodenum
}

Authors

\section{Dr Ezhilvizhi Alavandar, Dr Teleflo}

\section{Introduction}

Brunner gland adenoma is a rare tumour of the duodenum and presented as obstructive symptoms related to size of the lesions.

\section{Clinical Picture}

32 years old female presented to gastroenterology department for pain abdomen and not relieved by medications.

\section{Investigations}

Upper GI endoscopy performed. There was a huge polyp $>5 \mathrm{~cm}$ seen in the duodenum I part. Mild erosions were noted on the surface.

Complete Hemogram - normal picture.

Patient was subjected to surgery and polyp was sent for histopathologic examination.

\section{Macroscopic Findings}

Received a polyp measuring $5 \mathrm{~cm}$ in size sent in $10 \%$ formalin, processed and sections were subjected for microscopic examination.

\section{Microscopic Findings}

Sections studied shows a polypoidal duodenal mucosa with mild erosion, minimal inflammation of lamina propria. The submucosal florid proliferation of Brunner glands arranged in lobules of varying sizes and numbers. The lobules extended to lamina propria separated by delicate fibrous septae, few cystically dilated glands with basal position of nuclei. No mitotic activity.

\section{Diagnosis}

Microscopic picture is that of Brunner gland adenoma.

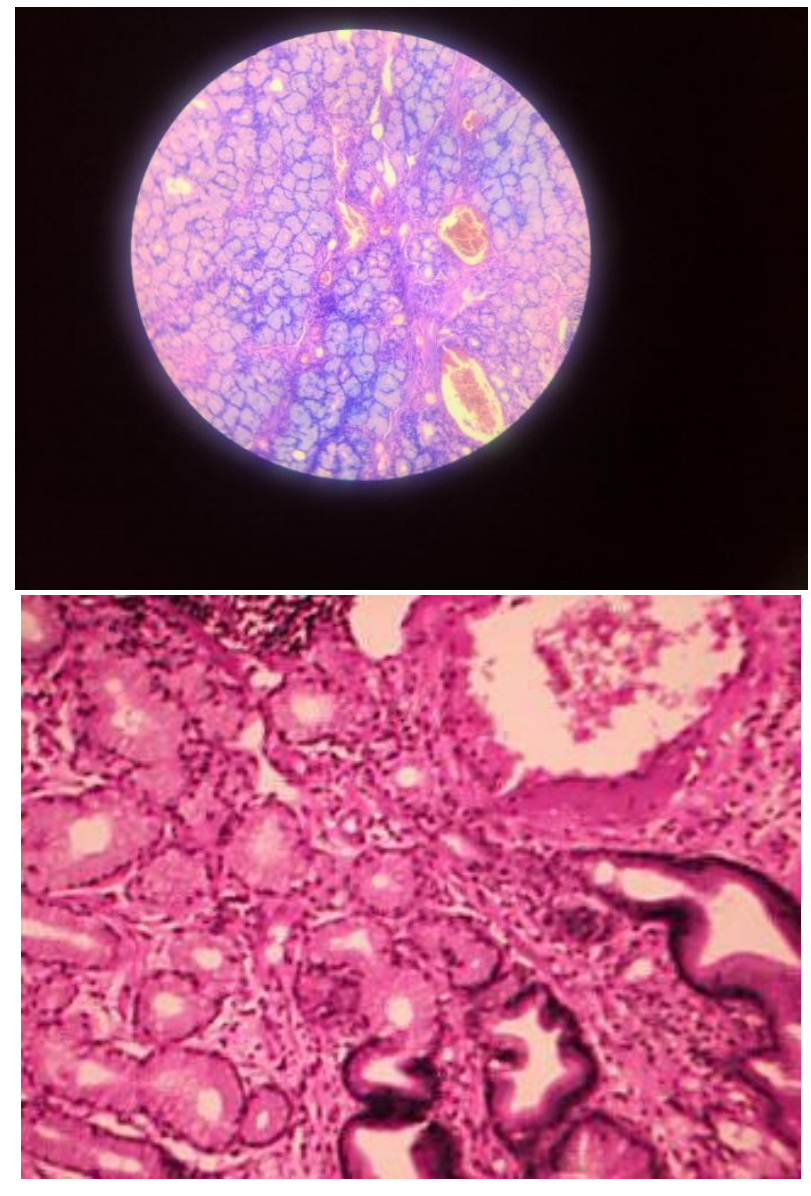




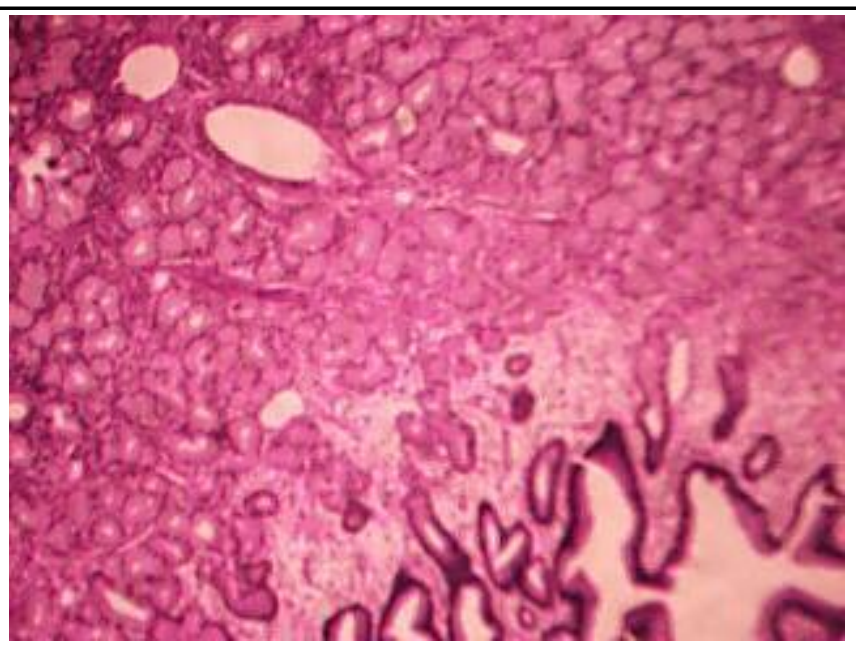

\section{Discussion}

Brunner glands are composed of normal neutral mucin secreting columnar cells with basally located nuclei arranged in lobules separated by fibrous septae. When they extend in to lamina propria creating a nodular surface on the mucosa. Brunner glands are predominantly located in the duodenal submucosa and extends to lamina propria focally transgress the muscularis mucosa. It is commonly seen in duodenal bulb. No sex or racial predilection. Usually an incidental finding at endoscopy performed for few other indications. In our case the polyp was causing obstruction and the size is larger than normal occurance.

No well documented evidence of dysplasia or carcinoma in brunner gland proliferation have yet been reported. The requirement to establish the diagnosis of adenoma - Presence of lobules of Brunner's glands within the mucosa at least 50\% of the height of the length of a biopsy specimen must be seen at light microscopic level.

This case is being presented for its rarity.

\section{References}

1. Surgical pathology of GI tract, liver, biliary tract and pancreas, second edition. Robert, D.ODZE, John.R.GOLD BLUM. PAGE NO. 448, 449

2. Gastrointestinal Pathology, Atlas Text $3^{\text {rd }}$ Edition Petu. G. Isaacson, Cecilia. M. Fenoglio. Preiser Page No. 472, 473

3. Surgical Pathology by Rosai \& Ackerman's $10^{\text {th }}$ Edition. Vo. I. Page No. 686, 687. 